Estrada López, M. (2014). La enajenación del trabajo en los manuscritos económico-filosóficos de 1844 de Karl Marx. Collectivus, Revista de Ciencias Sociales, 1, (1), 109-127. Julio - Diciembre. ISSN: 2382-4018

Recibido: 23/09/2013

Aceptado versión definitiva: 5/12/2013

\title{
LA ENAJENACIÓN DEL TRABAJO EN LOS MANUSCRITOS ECONÓMICO- FILOSÓFICOS DE 1844 DE KARL MARX
}

\author{
MARVIN ESTRADA LÓPEZ 1 \\ Universidad del Atlántico. Km.7 Antigua Vía Puerto Colombia \\ msestradal@gmail.com
}

\section{RESUMEN}

En el primero de sus Manuscritos económico-filosóficos de 1844 Karl Marx expone lo que él denomina como enajenación del trabajo. Esta relación se expresa de cuatro maneras distintas: Enajenación del producto, alienación de la actividad productiva, enajenación de la especie humana y enajenación de los demás seres humanos. En este artículo pretendo hacer un análisis de la idea de trabajo enajenado y una descripción de las cuatro expresiones presentes en los Manuscritos. Finalmente relacionaré el trabajo enajenado con el surgimiento de la propiedad privada y mostraré brevemente por qué Marx presenta al comunismo como una solución al problema que plantea la alienación del trabajo.

Palabras clave: Enajenación, actividad productiva, producto, especie humana, propiedad privada, capitalismo.

\footnotetext{
1 Filósofo. Investigador miembro de los grupos de investigación Holosapiens y Filosofía Práctica. Universidad del Atlántico.
} 
Estrada López, M. (2014). La enajenación del trabajo en los manuscritos económico-filosóficos de 1844 de Karl Marx. Collectivus, Revista de Ciencias Sociales, 1, (1), 109-127. Julio - Diciembre. ISSN: 2382-4018

\section{ALIENATED LABOUR IN MARX'S ECONOMIC AND PHILOSOPHIC MANUSCRIPTS OF 1844}

\section{ABSTRACT}

In the first of Marx's Economic and Philosophic Manuscripts of 1844, he exposes what he calls alienated labour. This relationship is expressed in four different ways: alienation from the product, alienation from productive activity, alienation from the human species-being and finally alienation from other human beings. In this paper I offer an analysis of the idea of alienated labour and a description of its four expressions that can be found in the Manuscripts. Finally I will try to relate alienated labour with the appearance of private property and I will try to show briefly why Marx introduces communism as a solution to the problems generated by the alienation of labour.

Key words: Alienation, productive activity, product, human species, private property, capitalism.

\section{Introducción}

Marx en sus Manuscritos económico-filosóficos de 1844 señala que el principal problema del sistema capitalista de producción es la relación de enajenación (o alienación) ${ }^{2}$ a la que somete al trabajador. La cual se expresa apartando a éste de su producto, de su actividad y de su esencia humana. La intención principal de este artículo es realizar una exposición de esta relación tal y como aparece en los Manuscritos. Al señalar el problema de la alienación del trabajo, Marx también tiene en mente proponer una solución o una superación del mismo. Es entonces cuando introduce el comunismo como una superación del problema de la enajenación que se presenta en el capitalismo. Si puede verse en el trabajo enajenado según Marx un enlace entre la crítica al sistema capitalista de producción y la introducción del comunismo como

\footnotetext{
2 Marx maneja, en los Manuscritos, los términos 'enajenación', 'alienación' e incluso 'extrañamiento' como sinónimos. Yo daré a ellos el mismo tratamiento en este escrito.
} 
Estrada López, M. (2014). La enajenación del trabajo en los manuscritos económico-filosóficos de 1844 de Karl Marx. Collectivus, Revista de Ciencias Sociales, 1, (1), 109-127. Julio - Diciembre. ISSN: 2382-4018

superación del mismo creo que se puede apreciar la importancia de este aspecto en la filosofía marxista.

Debo mencionar que en el presente escrito me centraré en la propuesta que se hace en los Manuscritos de 1844 y en el tratamiento que en esta obra hace el joven Marx de la relación de enajenación del trabajo. No pretendo hacer una exposición que abarque toda la obra de Karl Marx: Sólo me basaré en el planteamiento propuesto en la citada obra. La mencionada relación entre crítica del capitalismo e introducción del comunismo como alternativa puede verse en estos manuscritos. Sin embargo no debe olvidarse que mi intención principal es mostrar cómo explica Marx en esta obra la relación de enajenación del trabajo, cómo se manifiesta y qué consecuencias ésta tiene.

Marx en estos manuscritos hace una crítica a la Economía Política de su época, dominada principalmente por las ideas de David Ricardo y Adam Smith, entre otros. Él reconoce como ellos que el trabajo es el fundamento de toda la economía política. $\mathrm{Y}$ en las primeras partes del primer manuscrito se dedica Marx a hacer un análisis económico del trabajo, del trabajador, del salario, de la renta, del capital, etc. Sin embargo, no me centraré en el énfasis económico de esta primera parte del manuscrito. Quiero estudiar más bien el tratamiento antropológico y filosófico que recibe la categoría de trabajo en la parte final de dicho manuscrito.

Este aspecto se relaciona estrechamente con la crítica que hace Marx a la teoría económica de su época: Los economistas no hacen más que asumir hechos, los cuales primeramente deberían explicar, y a partir de ellos llegan a conclusiones equivocadas y establecen relaciones erradas entre conceptos económicos. Todo esto se debe a que la economía política ignora la base antropológica de dichos conceptos y de los procesos de los cuales se encarga. Una teoría económica que reconozca esta base será capaz de establecer las relaciones reales de los conceptos económicos tradicionales y podrá reconocer ciertas características de los procesos económicos, ocultas para la explicación que sólo asuma los hechos básicos. Una de estas relaciones es el carácter enajenado del trabajo en el sistema capitalista de producción. Mostraré a continuación en qué consiste tal enajenación del trabajo. 
Estrada López, M. (2014). La enajenación del trabajo en los manuscritos económico-filosóficos de 1844 de Karl Marx. Collectivus, Revista de Ciencias Sociales, 1, (1), 109-127. Julio - Diciembre. ISSN: 2382-4018

\section{Enajenación del trabajo}

¿Qué significa esto de enajenación? A mi modo de entender, la enajenación consiste en sentir algo propio como algo ajeno, en privarse de algo propio para verlo como algo no propio, como algo ajeno. Por ejemplo, me enajenaría de este trabajo si después de terminarlo y enviarlo, al verlo publicado lo considero como un escrito que no realicé, como un escrito que no me pertenece, que no contiene mis ideas ni mi interpretación del pensamiento de Marx. Si veo a mi propio escrito como algo totalmente extraño a mí puedo decir que me he enajenado de mi propio artículo y de mi propia interpretación del tema. Creo que este ejemplo sirve para ilustrar la concepción de enajenación que encuentro en el primer Manuscrito. La alienación del trabajo consiste principalmente en que se considera al trabajo, su producto y su actividad, como algo ajeno a la naturaleza del trabajador. El trabajo está enajenado cuando el trabajador no ve en esta labor su propia realización ni ve en el producto que produce su propia creación.

El trabajador enajenado de su trabajo no ve en él su propia naturaleza. El trabajador existe como trabajador en la medida en que posee una fuerza productiva transformadora que es capaz de crear productos. Esa es precisamente la naturaleza del trabajador. Pero cuando el trabajador no ve en esa fuerza productiva ni en el producto algo propio sino que los considera como algo totalmente ajeno, es decir cuando el trabajo es enajenado, tampoco puede considerar su propia naturaleza como algo propio. El trabajador ve a su naturaleza como algo ajeno, la enajenación del trabajo enajena al trabajador también de su propia naturaleza. Podría decirse que esta es una versión bastante simple de la relación de alienación presente en la obra de Marx. Tal vez lo es. Sin embargo, me sirve para resaltar los aspectos de esta relación que quiero abordar en este artículo.

Elster (1999) habla de la alienación como falta de auto-realización y como falta de autonomía del trabajador. También la describe como el dominio del capital sobre el trabajo. Pero todas estas caracterizaciones son 
Estrada López, M. (2014). La enajenación del trabajo en los manuscritos económico-filosóficos de 1844 de Karl Marx. Collectivus, Revista de Ciencias Sociales, 1, (1), 109-127. Julio - Diciembre. ISSN: 2382-4018

consecuencias del esquema inicial que he presentado y que aparece en el primer manuscrito. Fromm considera que:

[l]a enajenación (o 'extrañamiento') significa, para Marx, que el hombre no se experimenta a sí mismo como el factor activo en su captación del mundo sino que el mundo (la naturaleza, los demás y él mismo) permanece ajeno a él. Están por encima y en contra suya como objetos, aunque puedan ser objetos de su propia creación. La enajenación es, esencialmente, experimentar al mundo y a uno mismo pasiva, receptivamente, como sujeto separado del objeto. (Fromm, 2004, p. 55).

En la referencia anterior se aprecia la idea de la enajenación como una separación entre el hombre (trabajador) y el mundo, es decir una separación entre el trabajador y la naturaleza, los demás e incluso él mismo. La lectura de Fromm es acertada ya que de acuerdo con Marx, en el sistema de producción capitalista, el trabajador se enajena de su producto y de su actividad y se enajena también de la naturaleza, de la especie humana y de los demás hombres. Describiré en las páginas siguientes cómo Marx explica estos procesos de enajenación.

La relación de la enajenación del trabajo se expresa en los Manuscritos en cuatro relaciones: Enajenación del producto, enajenación de la actividad productiva, enajenación de la especie y enajenación de otros hombres. Ollman señala lo siguiente:

En su único tratamiento organizado del tema, Marx presenta la alienación como participando de cuatro amplias relaciones distribuidas de tal manera que cubren la totalidad de la existencia humana. Éstas son las relaciones del hombre con su actividad productiva, su producto, otros hombres y la especie. (Ollman, 1971, p. 137).

A continuación explicaré cada una de estas manifestaciones de la enajenación del trabajo. 
Estrada López, M. (2014). La enajenación del trabajo en los manuscritos económico-filosóficos de 1844 de Karl Marx. Collectivus, Revista de Ciencias Sociales, 1, (1), 109-127. Julio - Diciembre. ISSN: 2382-4018

\section{Enajenación del producto}

Para mostrar cómo se enajena el trabajador en el sistema capitalista de producción, Marx parte de lo que él llama 'un hecho económico contemporáneo'. Este hecho es el siguiente:

El obrero es más pobre cuanta más riqueza produce, cuanto más crece su producción en potencia y en volumen. El trabajador se convierte en mercancía tanto más barata cuantas más mercancías produce. La desvalorización del mundo humano crece en razón directa de la valorización del mundo de las cosas. El trabajo no sólo produce mercancías; se produce también a sí mismo y al obrero como mercancía, y justamente en la proporción en que produce mercancías en general. (Marx, 1974, p. 105).

Esta descripción parece poner la discusión frente a un problema meramente económico. Un problema que debe explicarse y no sólo asumirse. Pero lo que quiere mostrar Marx es que este hecho económico sólo puede explicarse satisfactoriamente apelando a un análisis, que yo califico como antropológico-filosófico, de la actividad productiva del hombre y de su esencia. Para Marx este hecho económico no es más que la expresión de la oposición entre el trabajador y su producto como ser extraño a él. El producto que el trabajador crea mediante su labor productiva, es decir, por su propio trabajo, se le opone a él como un ser extraño e independiente. En palabras del propio Marx esto se describe así:

Este hecho, por lo demás, no expresa sino esto: El objeto que el trabajo produce, su producto, se enfrenta a él como un ser extraño, como un poder independiente del productor. El producto del trabajo es el trabajo que se ha fijado en un objeto, que se ha hecho cosa; el producto es la objetivación del trabajo. La realización del trabajo es su objetivación. Esta realización del trabajo aparece en el estadio de la 
Estrada López, M. (2014). La enajenación del trabajo en los manuscritos económico-filosóficos de 1844 de Karl Marx. Collectivus, Revista de Ciencias Sociales, 1, (1), 109-127. Julio - Diciembre. ISSN: 2382-4018

Economía Política como des-realización del trabajador, la objetivación como pérdida del objeto y servidumbre a él, la apropiación como extrañamiento, como enajenación. (ob. Cit., 1974, p. 5).

La materia prima no llega a ser producto a menos que sea transformada por el trabajo de una persona. La materia prima cambia y se vuelve producto como efecto de la aplicación de la fuerza productiva del trabajador sobre la materia prima. Esta fuerza, este trabajo se objetiva, dice Marx, en el producto. Como se puede ver, para este filósofo la realización del trabajo es su objetivación. Cuando se realiza el trabajo se crea un producto, la expresión de la realización del trabajo es su objetivación. El producto es el trabajo que se ha fijado en un objeto, es el trabajo mismo hecho cosa. $Y$ en esa medida en el producto se fija la característica esencial del trabajador, su trabajo, su fuerza productiva. En el producto se objetiva la esencia del trabajador, el producto es la objetivación del trabajo. Y si el producto se presenta al trabajador como algo ajeno, extraño a él, lo que está sucediendo es que el trabajador se ha enajenado de su trabajo: Ahora ve como algo extraño el producto de su trabajo, su trabajo hecho cosa y en últimas ve su propia esencia como algo ajeno ${ }^{3}$. Marx, en el primer manuscrito, escribe:

El trabajador pone su vida en el objeto, pero a partir de entonces ya no le pertenece a él, sino al objeto. Cuanto mayor es la actividad, tanto más carece de objetos el trabajador. Lo que es producto de su trabajo, no lo es él. Cuanto mayor es la actividad, tanto más insignificante es el trabajador. (ob. Cit., 1974, p. 106).

Sucede, pues, lo que he tratado de describir anteriormente, es decir, el hecho económico que ha sido el punto de inicio de este análisis. Entre más produzca el trabajador más pobre es él mismo. Entre más productos cree el trabajador más parte de su vida pone en ellos y más parte de su vida se presenta como algo ajeno. Entre más produzca el trabajador menos vida éste

\footnotetext{
${ }^{3}$ En esta explicación Marx sigue mucho la idea de alienación religiosa planteada por Ludwig Feuerbach en La Esencia del Cristianismo.
} 
Estrada López, M. (2014). La enajenación del trabajo en los manuscritos económico-filosóficos de 1844 de Karl Marx. Collectivus, Revista de Ciencias Sociales, 1, (1), 109-127. Julio - Diciembre. ISSN: 2382-4018

poseerá. Como dice Marx "lo que es el producto de su trabajo, no lo es él” (ob. Cit., 1974, p. 106).

Así se ve, en consecuencia, cómo se configura la primera manifestación de la enajenación del trabajo: La alienación del producto. En palabras del filósofo alemán:

La enajenación del trabajador en su producto significa no solamente que su trabajo se convierte en un objeto, en una existencia exterior, sino que existe fuera de él, independiente, extraño, que se convierte en un poder independiente frente a él; que la vida que ha prestado al objeto se le enfrenta como cosa extraña y hostil. (Ob. Cit., 1974, p. 106).

El producto se presenta como algo ajeno a su productor, al trabajador que ha ejercido su fuerza de trabajo para crearlo. Se presenta como algo extraño al trabajador que ha objetivado su vida en dicho producto. Este reino de los objetos se presenta pues como un reino extraño y ajeno cuya fuerza aumenta en la medida en que aumenta el volumen de la producción. Cuanto más fuerte este reino es, más pobre es el trabajador y más parte de su vida ha perdido. La vida del trabajador se va con el producto que fabrica y entre más produzca, mayor parte de su vida se irá y se le presentará como algo extraño.

En esto consiste la enajenación del producto del trabajo y así se puede apreciar que cuanto mayor sea la producción del trabajador más miserable éste será y más pobre su vida será. La enajenación del trabajo expresada como enajenación del producto ha permitido explicar, y no sólo asumir, el hecho económico que se tomó como punto de partida, el cual es una terrible consecuencia del sistema capitalista de producción ${ }^{4}$. Entonces el trabajo deja al trabajador miseria mientras que ofrece beneficios a otros, el trabajo "produce palacios, pero para el trabajador chozas" (ob. Cit., 1974, p. 108). A este punto volveré más adelante.

\footnotetext{
${ }^{4}$ Y se ha llegado a la explicación de un hecho económico a partir de conceptos y relaciones que no son propios de la Economía Política sino que más bien pertenecen al ámbito filosófico. La reflexión filosófica ha permitido, según Marx, ofrecer una adecuada explicación de un hecho económico.
} 
Estrada López, M. (2014). La enajenación del trabajo en los manuscritos económico-filosóficos de 1844 de Karl Marx. Collectivus, Revista de Ciencias Sociales, 1, (1), 109-127. Julio - Diciembre. ISSN: 2382-4018

\subsection{Enajenación de la naturaleza}

Otra consecuencia negativa de la enajenación del producto del trabajo es la relación de enajenación entre el trabajador y la naturaleza. Como decía anteriormente, el trabajador ejerce su fuerza productiva sobre materias primas. Esta materia prima existe de alguna manera independientemente del trabajador. Este material sobre el que se realiza el trabajo es lo que Marx denomina naturaleza. La naturaleza es el material en el que se ejerce la fuerza productiva, es el material del cual y a través del cual se producen cosas. Así es claro ver que el "trabajador no puede crear nada sin la naturaleza, sin el mundo exterior sensible. Esta es la materia en que su trabajo se realiza, en la que obra, en la que y con la que produce" (ob. Cit., 1974, p. 107).

También es fácil notar que la naturaleza ofrece al trabajador sus medios de existencia en tanto que trabajador debido a que le proporciona el material sobre el cual aplicar su fuerza laboral. Y por la misma razón la naturaleza ofrece al trabajo sus medios de existencia. Pero también ofrece los medios de existencia al trabajador en tanto hombre, sujeto físico. De la naturaleza el hombre obtiene su alimento, su vestido, etc. La naturaleza también ofrece los medios de existencia del trabajador como sujeto físico. Axelos señala acertadamente que "El hombre trabaja para vivir. A diferencia de los animales, él trabaja para arrancarle a la Naturaleza los medios que le permitirán satisfacer sus necesidades naturales" (Axelos, 1976, p. 53).

El trabajador se apropia pues de la naturaleza, de los medios que ella le proporciona. Pero tanto más se apropie él de la naturaleza, es decir tanto más ejerza su actividad productiva en ella y cree por consiguiente productos, más se priva él mismo de sus medios de existencia. El trabajador se apropia de la naturaleza y crea productos, estos productos se le opondrán como algo ajeno, se enajena el trabajador de su producto y en últimas se enajena de la naturaleza que le proporcionó los medios para crear el producto. Así pues entre más se apropie de la naturaleza, más se enajenará de ella y más se privará de sus medios de existencia. Al operar el trabajo sobre la materia prima se crea el 
Estrada López, M. (2014). La enajenación del trabajo en los manuscritos económico-filosóficos de 1844 de Karl Marx. Collectivus, Revista de Ciencias Sociales, 1, (1), 109-127. Julio - Diciembre. ISSN: 2382-4018

producto, entre más se apropie el trabajador de la naturaleza, más producto crea y más fuerza da al reino de los objetos que le es ajeno.

Este reino de los objetos adquiere ahora su gran poder y esclaviza al trabajador. Esto sucede debido a que como la naturaleza ofrece los medios de existencia del trabajador en tanto que trabajador y sujeto físico, los objetos que resultan de la acción del trabajo sobre la naturaleza (naturaleza transformada) proporcionarán los medios de existencia del trabajador. Así el trabajador se convierte en esclavo del objeto porque éste le permite existir, porque los objetos le proporcionan sus medios de existencia.

\section{Enajenación de la actividad productiva}

Se ha visto hasta ahora cómo el trabajador se enajena del producto de su labor productiva. Pero surge la siguiente pregunta: ¿Cómo podría presentarse el producto como algo ajeno sin que la labor productiva que lo ha creado se presente ella misma como algo ajeno al trabajador?

Para Marx, si el producto es algo extraño al trabajador, la actividad por la cual éste fue creado también es algo extraño a él. Por ello, escribe:

Pero el extrañamiento no se muestra sólo en el resultado, sino en el acto de la producción, dentro de la actividad productiva misma. ¿Cómo podría el trabajador enfrentarse con el producto de su actividad como con algo extraño si en el acto mismo de la producción no se hiciese ya ajeno a sí mismo? El producto no es más que el resumen de la actividad, de la producción. Por tanto, si el producto del trabajo es la enajenación, la producción misma ha de ser la enajenación activa, la enajenación de la actividad. (Marx, 1974, p. 108).

El extrañamiento del producto es resultado del extrañamiento de la producción misma. La enajenación del producto es sólo una versión resumida de la enajenación de la actividad productiva. ¿En qué consiste esta enajenación de la actividad productiva? Consiste en que el trabajo, la labor productiva, no es considerado como parte de la esencia del trabajador, se le 
Estrada López, M. (2014). La enajenación del trabajo en los manuscritos económico-filosóficos de 1844 de Karl Marx. Collectivus, Revista de Ciencias Sociales, 1, (1), 109-127. Julio - Diciembre. ISSN: 2382-4018

considera algo extraño al mismo. Por ende el trabajador no puede realizarse en la actividad laboral sino que, por el contrario, en ella lo que hace es autonegarse. Su trabajo no es un deleite sino un suplicio, no es una posibilidad sino una obligación, no es para el trabajador mismo sino para otro. Escribe Marx lo siguiente:

¿En qué consiste, entonces, la enajenación del trabajo? Primeramente en que el trabajo es externo al trabajador, es decir, no pertenece a su ser; en que en su trabajo, el trabajador no se afirma, sino que se niega; no se siente feliz, sino desgraciado; no desarrolla una libre energía física y espiritual, sino que mortifica su cuerpo y arruina su espíritu. (ob. Cit., 1974, p. 109).

En las condiciones que aquí se describen es fácil ver y entender por qué el trabajador se siente feliz mientras descansa y en cambio se siente infeliz cuando trabaja. Si el trabajo no es auto-realización del trabajador entonces es una obligación. El trabajador no realiza su actividad de manera libre y voluntaria sino que lo hace forzado, es realmente un trabajo forzado lo que él realiza. Por eso el trabajo no es la satisfacción directa de la necesidad del hombre de auto-realizarse sino más bien es visto como un medio para satisfacer otras necesidades. $Y$ el trabajo no se ve como algo propio sino como algo que es de otro.

Lo que el trabajador cambia por el salario que recibe es su fuerza productiva. El trabajador se despoja de su actividad laboral para conseguir un salario que le permita satisfacer otras necesidades. El trabajo como actividad es pues una actividad que el trabajador identifica como algo ajeno (Cfr. Marx, 1974 , p. 109). Esta segunda manifestación de la enajenación del trabajo, la enajenación de la actividad productiva, constituye la 'auto-enajenación' del trabajador. El trabajador ve en su propia actividad algo ajeno. 
Estrada López, M. (2014). La enajenación del trabajo en los manuscritos económico-filosóficos de 1844 de Karl Marx. Collectivus, Revista de Ciencias Sociales, 1, (1), 109-127. Julio - Diciembre. ISSN: 2382-4018

\section{Enajenación de la especie humana}

Como notaba líneas más arriba, la enajenación del trabajo expresada como producto enajenado llevaba como consecuencia a la relación de enajenación entre el hombre y la naturaleza. $Y$ en la sección anterior he señalado que el hombre se enajena de su propia actividad productiva, y en términos de Marx eso equivale a decir que se enajena de su propia actividad vital puesto que para este filósofo la vida es actividad. Él mismo afirma "pues qué es la vida sino actividad" (ob. Cit., 1974, p. 110). De estos dos resultados nefastos del sistema capitalista de producción, Marx extrae la tercera manifestación o consecuencia de la enajenación del trabajo: La enajenación de la especie humana. Si el hombre se enajena de la naturaleza y de su propia actividad vital se enajena pues de la especie humana, del ser genérico del hombre, concepto tomado del pensamiento de Feuerbach.

Ya he indicado que la enajenación del trabajo enajena al hombre tomado como individuo de su esencia, de su actividad vital, de su vida. Marx ahora quiere mostrar que la alienación del trabajo también tiene como resultado la enajenación de la vida de la especie humana, enajenación de lo que él llama vida genérica. Señalaré ahora cómo se llega a esta afirmación.

Para Marx el hombre es un ser genérico porque "se relaciona consigo mismo como el género actual, viviente, porque se relaciona consigo mismo como un ser universal y por eso libre." (ob. Cit., 1974, p. 110.). Al igual que Feuerbach, Marx diferencia al hombre de los animales en la medida en que es capaz de ser consciente de sí mismo no sólo como individuo sino como especie, como género. La conciencia del hombre es ilimitada, universal. En cambio, la conciencia de los animales es muy limitada. Como lo expone Feuerbach (2006, p. 14): "la conciencia de una oruga, cuya vida y esencia está limitada a determinadas especies de plantas, no se extiende tampoco más allá de ese terreno limitado: Ella distingue estas plantas de las demás; pero más no sabe". La conciencia del hombre es universal y también lo es su esencia, su ser, puesto que, otra vez en palabras de Feuerbach, "el límite del ser es 
Estrada López, M. (2014). La enajenación del trabajo en los manuscritos económico-filosóficos de 1844 de Karl Marx. Collectivus, Revista de Ciencias Sociales, 1, (1), 109-127. Julio - Diciembre. ISSN: 2382-4018

también el límite de la conciencia." (ob. Cit., 2006, p. 14). La conciencia humana es universal y abarca toda la naturaleza, a diferencia de la conciencia limitada que presentan los animales. Por ende, la esencia humana también es universal, es un ser genérico.

La vida genérica de la especie humana es mucho más amplia que la vida de cualquier otra especie animal. Se puede decir que la vida genérica de una especie es el ámbito de la naturaleza de la que dicha especie vive. En el caso de la oruga, la vida genérica de dicha especie de oruga se reduce solamente a las determinadas especies de plantas de las que se alimenta, sabe cuáles son las que come y las distingue de las demás pero sólo es limitado ámbito de la naturaleza es el que le interesa a esa especie. En el caso de la especie humana el ámbito de la naturaleza es mucho más amplio, abarca toda la naturaleza. El hombre como especie vive de la naturaleza en toda su extensión. Su vida genérica es por ende universal y no limitada como la de la oruga. Dice Marx:

La universalidad del hombre aparece en la práctica justamente en la universalidad que hace de la naturaleza todo su cuerpo inorgánico, tanto por ser (1) un medio de subsistencia inmediato, como por ser (2) la materia, el objeto y el instrumento de su actividad vital. (Marx, 1974, pp. 110-111).

El hombre pues vive de la naturaleza y no de un limitado ámbito de ella sino que vive de la naturaleza toda, tomada en toda su extensión. La naturaleza le ofrece los medios de subsistencia inmediatos y además le permite ejercer su actividad vital. Pero en el sistema capitalista de producción ambos aspectos se encuentran en relación de enajenación con el hombre. He señalado que la naturaleza se enajena del trabajador y que también se aliena la actividad productiva del mismo. Estas características de la alienación, que ya he considerado en páginas anteriores, son las que llevan a Marx a inferir que la esencia de la especie, que la vida genérica del hombre también está enajenada. Escribe: 
Estrada López, M. (2014). La enajenación del trabajo en los manuscritos económico-filosóficos de 1844 de Karl Marx. Collectivus, Revista de Ciencias Sociales, 1, (1), 109-127. Julio - Diciembre. ISSN: 2382-4018

Como quiera que el trabajo enajenado (1) convierte a la naturaleza en algo ajeno al hombre, (2) lo hace ajeno de sí mismo, de su propia función activa, de su actividad vital, también hace del género algo ajeno al hombre; hace que para él la vida genérica se convierta en medio de la vida individual. (ob. Cit., 1974, p. 111).

La enajenación de la naturaleza y de la actividad vital del hombre lo enajena a su vez de la especie humana misma. La actividad productiva del trabajador era considerada como la actividad vital del mismo, pero sólo se le estaba considerando individualmente. Ahora se ve pues que esa actividad productiva vital es además la actividad vital de la especie humana. Al apropiarse por medio de ella de la totalidad de la naturaleza, de su universalidad, se realiza la esencia del género humano. Esta es la vida genérica de la especie humana. Por ende la alienación de esta actividad no es sólo la alienación con respecto al trabajador individual sino que ahora se toma con respecto a la especie humana en general.

La alienación del producto y con ella la alienación de la vida del trabajador y de la naturaleza conllevan a la relación de alienación entre el hombre y su vida genérica, su especie en general. La enajenación del trabajo conduce ahora a la enajenación de la vida genérica de la especie humana, conduce a la enajenación del género humano. En palabras de Marx:

Por eso precisamente es sólo en la elaboración del mundo objetivo en donde el hombre se afirma realmente cono un ser genérico. Esta producción es su vida genérica activa. Mediante ella aparece la naturaleza como su obra y su realidad. El objeto del trabajo es por eso la objetivación de la vida genérica del hombre, pues éste se desdobla no sólo intelectualmente, como en la conciencia, sino activa y realmente, y se contempla a sí mismo en un mundo creado por él. Por esto el trabajo enajenado, al arrancar al hombre el objeto de su producción, le arranca su vida genérica (ob. Cit., 1974, pp. 112-113). 
Estrada López, M. (2014). La enajenación del trabajo en los manuscritos económico-filosóficos de 1844 de Karl Marx. Collectivus, Revista de Ciencias Sociales, 1, (1), 109-127. Julio - Diciembre. ISSN: 2382-4018

\section{Enajenación de otros hombres}

La inmediata consecuencia de la relación de enajenación entre el hombre y la especie humana es la relación de enajenación entre el hombre y los demás miembros de la especie humana. La enajenación de otros hombres es una consecuencia que se sigue de la enajenación de la vida genérica que se acaba de considerar. Como dice Marx, "en general, la afirmación de que el hombre está enajenado de su ser genérico quiere decir que un hombre está enajenado del otro, como cada uno de ellos está enajenado de la esencia humana" (ob. Cit., 1974, p. 113).

El hombre verá en otros individuos humanos seres ajenos a él. Si el hombre está enajenado de la especie humana todos los individuos pertenecientes a dicha especie se le presentarán de la misma manera que lo hace la vida genérica: se le presentarán como algo ajeno, como algo extraño a él mismo. Marx lo expresa de la siguiente manera:

Una consecuencia inmediata del hecho de estar enajenado el hombre del producto de su trabajo, de su actividad vital, de su ser genérico, es la enajenación del hombre respecto del hombre. Si el hombre se enfrenta consigo mismo, se enfrenta también al otro. Lo que es válido respecto de la relación del hombre con su trabajo, con el producto de su trabajo y consigo mismo, vale también para la relación del hombre con el otro y con el trabajo y el producto del trabajo del otro. (ob. Cit., 1974, p. 113).

En la misma dirección Axelos (1976, p. 53) afirma que "la esencia del trabajo es social". Teniendo en cuenta esto es claro ver por qué la enajenación del trabajo produce la enajenación de otros individuos de la especie. Si es el trabajo esencialmente social, la alienación del trabajo debe necesariamente conducir a la enajenación de la sociedad, esto es, a la enajenación del trabajador con respecto a los otros miembros de la sociedad en la que vive, es decir, con respecto a los otros seres humanos. 
Estrada López, M. (2014). La enajenación del trabajo en los manuscritos económico-filosóficos de 1844 de Karl Marx. Collectivus, Revista de Ciencias Sociales, 1, (1), 109-127. Julio - Diciembre. ISSN: 2382-4018

\section{Enajenación del trabajo y la propiedad privada}

En las secciones anteriores se ha podido apreciar cómo el trabajador se siente enajenado de su producto, de su actividad, de la naturaleza, de su especie y de los demás hombres. El trabajador ve en todos ellos cosas ajenas a sí mismo. No reconoce ni su producto ni su actividad como cosas propias de su vida y de su esencia, siendo que ambos son objetivación de su vida, de su esencia y de su actividad vital.

Si ahora fijo la atención en la enajenación del producto, cabe plantear la siguiente pregunta: si el producto del trabajo no le pertenece al trabajador (puesto que lo considera ajeno a él), entonces ¿a quién pertenece ese producto? Debe pertenecer a otro, a otro hombre que no es el trabajador mismo. Mientras el trabajador está enajenado y es despojado de su producto otro hombre que no es el trabajador se apropia de este producto. Otro hombre es quien posee dicho producto y disfruta de sus beneficios mientras que el trabajador sufre de carencias y miseria. Marx lo explica de la siguiente manera:

Si el producto del trabajo no pertenece al trabajador, si es frente a él un poder extraño, esto sólo es posible porque pertenece a otro hombre que no es el trabajador. Si su actividad vital es para él dolor, ha de ser goce y alegría vital de otro (Marx 1974, p. 114).

Las relaciones del trabajador con su producto y su actividad serán las mismas relaciones que se establecerán entre él y el dueño del producto. Si el trabajador ve en el producto un objeto ajeno a sí mismo y una fuerza hostil y dominadora verá también en el dueño del producto una persona diferente a sí mismo, una persona hostil y dominadora. Para Marx, como señalaba en la sección anterior, las relaciones de enajenación entre el trabajador y el producto y entre el trabajador y su actividad determinarán las relaciones entre el trabajador y el dueño del producto y entre el trabajador y el dueño de la fábrica donde trabaja. Dice Marx: 
Estrada López, M. (2014). La enajenación del trabajo en los manuscritos económico-filosóficos de 1844 de Karl Marx. Collectivus, Revista de Ciencias Sociales, 1, (1), 109-127. Julio - Diciembre. ISSN: 2382-4018

Si él (el hombre, el trabajador), pues, se relaciona con el producto de su trabajo, con su trabajo objetivado, como con un objeto poderoso, independiente de él, hostil, extraño, se está relacionando con él de forma que otro hombre independiente de él, poderoso, hostil, extraño a él, es el dueño de este objeto. Si él se relaciona con su actividad como con una actividad no libre, se está relacionando con ella como con la actividad al servicio de otro, bajo las órdenes, la compulsión y el yugo de otro. (ob. Cit., 1974, p. 115).

La oposición entre el trabajador y el producto de su trabajo, entre el trabajador y su actividad productiva se traslada al ámbito de las relaciones entre el trabajador y el otro hombre distinto a él que posee, a diferencia de él, el producto del trabajo. De la misma manera hostil que se relaciona el trabajador con su producto se relacionará él con el dueño del producto. La enajenación del trabajo es responsable pues de la oposición hostil entre el trabajador y el capitalista, ahora dueño del producto.

El capitalista es el hombre que no es el trabajador y que se apropia del producto de su trabajo. Esto es posible en la medida en que el trabajador "al enajenarse de su propia actividad posesiona al extraño de la actividad que no le es propia" (ob. Cit., 1974, p. 115). El sistema capitalista de producción hace que el trabajador se enajene de su producto y de su actividad y al mismo tiempo abre la posibilidad de que otro hombre, que no es el trabajador, se apropie de su producto y de su actividad y así surja como propietario, como capitalista. Esta apropiación del no-trabajador del producto del trabajo, del trabajo mismo es lo que Marx denominará la relación de la propiedad privada. Esta relación está determinada por la apropiación de un no-trabajador del producto del trabajo.

La relación de la propiedad privada es un lado de la moneda. El otro lado de esta moneda es la relación de enajenación del trabajo que he analizado en este trabajo. Sólo cuando hay un producto sin dueño, esto es el resultado de la enajenación del trabajo, es posible la apropiación de dicho producto, esto es el surgimiento de la propiedad privada. Por ello, es fácil ver que, la propiedad 
Estrada López, M. (2014). La enajenación del trabajo en los manuscritos económico-filosóficos de 1844 de Karl Marx. Collectivus, Revista de Ciencias Sociales, 1, (1), 109-127. Julio - Diciembre. ISSN: 2382-4018

privada es la consecuencia necesaria del trabajo enajenado. El mismo Marx afirma que "la propiedad privada es, pues, el producto, el resultado, la consecuencia necesaria de trabajo enajenado, de la relación externa del trabajador con la naturaleza y consigo mismo" (ob. Cit., 1974, p. 116).

\section{Conclusiones}

Se ha podido ver, pues, cómo el sistema de producción capitalista lleva al trabajador a enajenarse de su producto, de su actividad, de la naturaleza, de su especie y de los otros hombres. Todo esto lleva a la miseria del trabajador y al beneficio del capitalista. Lleva a que el trabajador se vuelva un esclavo de los objetos, que se aleje de su actividad vital, de la naturaleza y de los demás hombres. El hombre se mantiene en una relación de servidumbre con respecto al producto, a los objetos y a los dueños de ellos.

Marx critica al sistema capitalista de producción por la miseria del trabajador y su enajenación, las cuales en últimas serán la miseria, la enajenación y la servidumbre de la humanidad. Sólo se podrán superar estos graves problemas si se supera al sistema capitalista. Se debe superar el esquema productivo en el cual el trabajador pierde su producto y con él su vida y su libertad. Se debe superar el sistema que conlleva a la enajenación del trabajador y del hombre en general. Por esto Marx afirma que se debe proponer un sistema alternativo en el cual se superen todas estas dificultades.

Hay que señalar enfáticamente que la solución no es otorgar mayores salarios a los trabajadores. La verdadera solución, según Marx, es cambiar radicalmente el modelo productivo del sistema capitalista, ese modelo de producción que esclaviza y enajena a los hombres. Y si la consecuencia de la enajenación del trabajo es la propiedad privada, la superación de la enajenación misma pasa por la abolición de la propiedad privada. Eliminar la relación de la propiedad privada es eliminar la posibilidad de que alguien ajeno se apropie del producto de los trabajadores. Es eliminar la posibilidad de que se enajene el producto de su productor. Abolir la propiedad privada sería abolir la posibilidad de la enajenación del trabajo. $Y$ aquí surge el comunismo, en 
Estrada López, M. (2014). La enajenación del trabajo en los manuscritos económico-filosóficos de 1844 de Karl Marx. Collectivus, Revista de Ciencias Sociales, 1, (1), 109-127. Julio - Diciembre. ISSN: 2382-4018

tanto sistema que elimina la propiedad privada, como una superación de los problemas del sistema de producción capitalista. En últimas lo que Marx quiere es que el hombre se reencuentre con su esencia, con su trabajo y con su vida. Lo que se busca es superar la enajenación y la esclavitud a la que se somete el hombre en el capitalismo.

\section{Referencias bibliográficas}

Axelos, K. (1976). Alienation, Praxis and Techne in the Thought of Karl Marx. (transl. Ronald Bruzina). Austin/London: University of Texas Press.

Elster, J. (1999). An Introduction to Karl Marx. Cambridge: Cambridge University Press.

Feuerbach, L. (2006). La Esencia del Cristianismo (trad. Franz Huber). Buenos Aires: Claridad.

Fromm, E. (2004). Marx y su concepto del hombre (trad. Julieta Campos). México: Fondo de Cultura Económica.

Marx, K. (1974). Manuscritos: economía y filosofía (trad. Francisco Rubio Llorente). Madrid: Alianza Editorial.

Ollman, B. (1971). Alienation. Marx's Conception of Man in Capitalist Society. Cambridge: Cambridge University Press. 